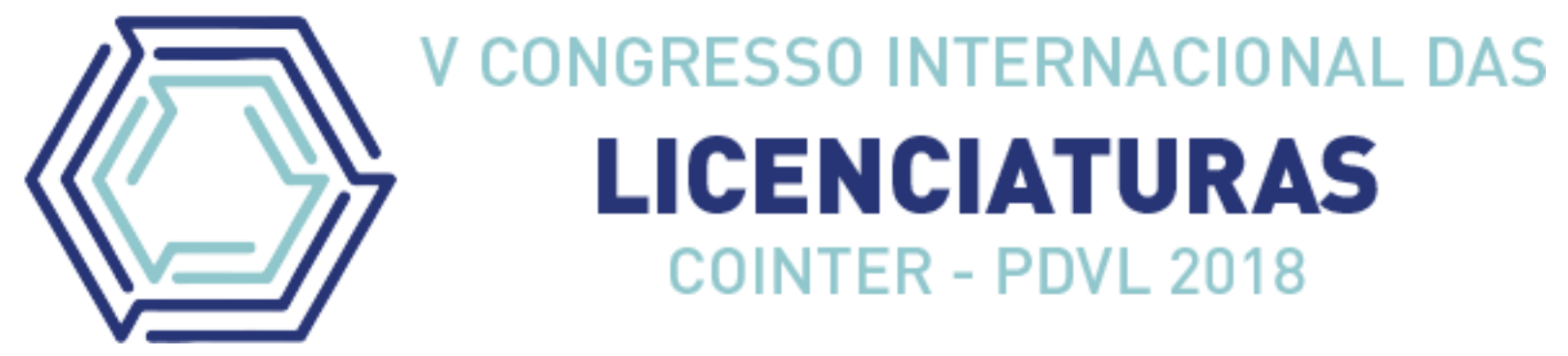

\title{
O PROGRAMA PIBID: ANÁLISE E REFLEXÃO DAS PROPOSTAS DA CAPES DE 2013 A 2018
}

\section{THE PIBID PROGRAM: ANALYSIS AND REFLECTION OF PROPOSALS CAPES FROM 2013 TO 2018}

\author{
Apresentação: Comunicação Oral \\ Natália Pires Linhares ${ }^{1}$; Jéter Correia de Lima ${ }^{2}$; Maria Trinidad Pacherrez Velasco ${ }^{3}$ \\ DOI: https://doi.org/10.31692/2358-9728.VCOINTERPDVL.2018.00118
}

\section{Resumo}

Esta pesquisa se propõe analisar e refletir a respeito das propostas de 2013 a 2018 para o Programa de Iniciação à Docência (PIBID) emitido pela Coordenação de Aperfeiçoamento de Pessoal de Nível Superior (CAPES). Utilizando-se da pesquisa documental, traduzida na leitura e análise dos documentos emitidos para as Instituições de Ensino Superior (IES) do Brasil, a saber, as Portarias no 096 de 18 de julho de 2013, n $^{\circ} 046$ de 11 de abril de 2016 e ${ }^{\circ}$ 45 de 12 de março de 2018, nas quais aprova-se o regulamento do Programa PIBID, procuramos identificar mudanças implementadas e as consequências que estas possam ter gerado na vida acadêmica e profissional de todos que formam parte direta e indireta do programa PIBID.

Palavras-Chave: PIBID de 2013 a 2018, Análise e reflexão, Portarias CAPES

\begin{abstract}
This research proposes to analyze and reflect on the proposals from 2013 to 2018 for the Initiation to Teaching Program (PIBID) issued by the Coordination of Improvement of Higher Education Personnel (CAPES). Using the documentary research, translated into the reading and analysis of the documents issued to the Institutions of Higher Education (IES) of Brazil, namely, Portarias $\mathrm{n}^{\mathrm{o}} 096$ of July 18, 2013, $\mathrm{n}^{\mathrm{o}} 046$ of April 11, 2016 and $\mathrm{n}^{\circ} 45$ of March 12, 2018 in which the regulation of the PIBID Program is approved, we try to identify changes implemented and the consequences that these could have generated in the academic and professional life of all that form a direct and indirect part of the PIBID program.
\end{abstract}

Keywords: PIBID 2013 a PIBID 2018, Analysis and reflection, CAPES documents.

\section{Introdução}

Durante a vida acadêmica, se faz necessário que o estudante de licenciatura reflita sobre seu papel enquanto futuro professor de uma determinada área de conhecimento, pense

\footnotetext{
${ }^{1}$ Licenciatura em Letras - Espanhol, IFRN, nataliaplinhares@gmail.com

${ }^{2}$ Licenciatura em Letras - Espanhol, IFRN, jetercorreia@gmail.com

${ }^{3}$ Doutora, professora do IFRN/CNAT. maria.velasco@ifrn.edu.br
} 
quais serão suas práticas educativas e que metodologias serão adotadas em sala de aula. Para isso, cabe à instituição formadora dispor de espaço onde o estudante possa vivenciar as práticas pedagógicas e metodológicas em ambiente adequado e que correspondam à sua profissão. Ali serão postos em prática os conhecimentos adquiridos no decorrer do curso, contribuindo em sua formação. $\mathrm{O}$ estudante transforma realidades, imprimindo no espaço e tempo suas práticas pedagógicas como produtor de conhecimento, buscando levar qualidade para a sua formação profissional e para a vida dos seus futuros alunos.

Neste contexto, a existência do Programa Institucional de Bolsas de Iniciação à Docência, doravante PIBID, programa do Governo Federal, com base legal nas leis $\mathrm{n}^{\mathrm{o}}$ 9.394/1996 e 11.273/2006 e no Decreto $\mathrm{n}^{\mathbf{0}} 7.219 / 2010^{4}$, tem se configurado como peça de grande significado e oportuna implementação nas Instituições de Ensino Superior (IES), possibilitando que a preparação teórico-prática do licenciando seja uma realidade, e contribuindo também para a permanência do licenciando na IES até a culminação dos estudos.

O nosso propósito neste trabalho é o de analisar a principal fonte que ergue o programa PIBID, as portarias da CAPES do período 2013 até a atual (2018), no intuito de identificar as mudanças implementadas em cada uma das sucessivas ofertas e as consequências que estas mudanças possam ter gerado na vida acadêmica e profissional de todos que formam parte direta e indireta do programa PIBID, com ênfase para o futuro docente.

Utilizamo-nos da pesquisa bibliográfica e documental para investigar os documentos emitidos pela CAPES, pontualmente as Portarias $n^{\circ} 096$ de 18 de julho de 2013, $n^{\circ} 046$ de 11 de abril de 2016 e $\mathrm{n}^{\mathrm{o}} 45$ de 12 de março de 2018. Nesses documentos aprova-se o regulamento do Programa PIBID, o qual procuramos analisar, contrastivamente, na intenção de identificar mudanças e compreender o impacto delas no desenvolvimento do programa, desde e para cada um dos agentes atuantes no programa.

Acreditamos na relevância deste trabalho, face à necessidade de compreender panoramicamente os movimentos que o Ministério de Educação cria para a comunidade acadêmica e gerar reflexão em prol de uma consciência acadêmica e cidadã.

\section{Fundamentação Teórica}

Foi com a Lei de Diretrizes e Bases da Educação Nacional, de 1996, que se percebeu

\footnotetext{
4 Portaria no 096 de 18 de julho de 2013, pág. 2. Disponível em: <https://www.capes.gov.br/images/stories/download/legislacao/Portaria_096_18jul13_AprovaRegulamentoPI BID.pdf>. Acesso em: 02 set. 2018.
} 
um maior investimento em políticas educacionais na formação de professores para a educação básica, tendo por objetivo inicial a melhoria na educação para o Brasil. Dentre essas iniciativas do governo federal, se encontra o PIBID, dirigido pela CAPES, que se concretiza por meio de parceria entre as IES e as Escola-Campo - escolas estaduais -, criando-se assim condições para que o estudante de licenciatura, futuro professor, possa observar, vivenciar, compreender e refletir o processo educativo em que está inserido e sobre a realidade social sua e da comunidade escolar participante do projeto.

O PIBID teve início no ano de 2009, segundo consta no volume 41 do relatório da Fundação Carlos Chagas (FUNDAÇÃO CARLOS CHAGAS, 2014, p. 05). Participaram nesse ano 43 instituições federais de ensino superior, totalizando 3.088 bolsistas. No entanto, outras instituições passaram a participar do projeto e no ano de 2014 "o PIBID alcançou 90.254 bolsistas, distribuídos em 855 campi de 284 instituições formadoras públicas e privadas". Com isso, houve um aumento espetacular na quantidade de instituições e também de bolsistas que aderiram ao programa comprovando a eficácia do incentivo na formação de professores.

Esse programa não é simplesmente um programa de bolsas, é um projeto de iniciação à docência para alunos que estão matriculados em cursos de licenciatura. Conforme o relatório da Fundação Carlos Chagas (FUNDAÇÃO CARLOS CHAGAS, 2014, p. 05), o PIBID tem por objetivo o aperfeiçoamento dos participantes e a valorização de sua formação. A Fundação ainda registra que nesse programa, "os alunos de licenciatura exercem atividades pedagógicas em escolas públicas de educação básica, contribuindo para a integração entre teoria e prática, para a aproximação entre universidades e escolas e para a melhoria de qualidade da educação brasileira". Para assegurar os resultados dessas atividades pedagógicas e educacionais, os bolsistas recebem orientação de coordenadores de área, que são os docentes dos cursos de licenciatura da instituição formadora; e dos supervisores, que são os docentes das escolas públicas onde exercem formalmente as suas atividades.

Por necessidade de aperfeiçoar e atualizar as normas do Programa PIBID, foi gerada a Portaria n 096/2013 de 18 de julho de 2013, que tem por finalidade aprovar o Regulamento do Programa PIBID, revogando a Portaria anterior de n⿳ 260 de 30 de outubro de 2010.

É a partir da Portaria no 096/2013 que logo é publicado o edital $n^{\circ} 061 / 2013$ ao qual o IFRN $^{5}$ se apresenta, aprovando o programa e começando com sucesso as atividades nele. Foi

\footnotetext{
${ }^{5}$ IFRN - Instituto Federal de Educação, Ciência e Tecnologia do Rio Grande do Norte.
} 
muito significativo e estimulante para os estudantes vivenciar este programa, pois o espaço de aprendizagem da docência expandiu-se à realidade de fato, permitindo testar a teoria recebida na IES.

Em meio a uma situação política bastante difícil no país com o impeachment da então presidente do Brasil, Dona Dilma Rouseff, em 2016, surge a Portaria n ${ }^{\circ}$ 46/2016 de 11 de abril de 2016, que revogava a Portaria n 096, de 18 de julho de 2013. Por um lado foi bem recebida pelos Municípios e Estados, uma vez que se passaria a receber ajuda dos bolsistas nas escolas que possuíam maiores dificuldades, porém as Universidades enxergaram as mudanças como uma ênfase no reforço escolar em língua portuguesa e matemática, com o intuito de melhorar os índices de aprendizagem ao invés de priorizar a formação do professor, razão de existir do programa.

O Fórum Nacional do PIBID - FORPIBID, que reúne os coordenadores institucionais do programa, divulgou por meio da internet um abaixo assinado e uma Nota de Repúdio pedindo a revogação imediata da Portaria no 46/2016. Dentre as justificativas constantes do documento, o FORPIBID alegou que, além da natureza de formação inicial de professores ter sido substituída pelo atendimento à demanda por reforço escolar, a Portaria determinava o fim dos subprojetos organizados pelos cursos de Licenciaturas; não mencionava áreas de conhecimento do PIBID, tais como Licenciatura em Educação Física, Ciência da Computação, Psicologia e Línguas Estrangeiras, por exemplo; e se omitia com relação à formação de professores para a etapa da Educação Infantil, bem como para as modalidades de Educação Especial, Profissional e Educação de Jovens e Adultos.

Em 15 de junho de 2016, a CAPES publicou a Portaria nº 84, de 14 de junho de 2016, revogando a Portaria n 46/2016. De acordo com Maria Helena Guimarães de Castro, então secretária executiva do Ministério da Educação (MEC), a revogação ocorreu porque a Portaria foi feita às pressas e sem previsibilidade. O comitê técnico do PIBID ficou encarregado de examinar o programa até o final de 2016 e definir planejamento para o ano de 2017.

Em 01 de março de 2018 a CAPES publicou o Edital n $n^{\circ} 7 / 2018$, chamada pública para apresentação de propostas de desenvolvimento de projetos de iniciação à docência nos cursos de licenciatura, em regime de colaboração com as redes de ensino, no âmbito do PIBID, que tem como público alvo os discentes licenciandos que estejam cursando a primeira metade de curso de licenciatura ofertado por IES, sejam elas públicas ou privadas com ou sem fins lucrativos, com o intuito de proporcionar a estes discentes uma aproximação prática com o 
cotidiano das escolas públicas de educação básica. Esse edital veio a substituir o edital $\mathrm{n}^{\circ}$ 061/2013.

Logo mais veio a público a Portaria Gab no 45 de 12 de março de 2018, que dispõe sobre a concessão de bolsas e o regime de colaboração nos Programa Residência Pedagógica e PIBID, o que gerou tranquilidade e processos de implementação nas IES para ambos os programas.

\section{Metodologia}

A metodologia de investigação aplicada neste trabalho é de cunho bibliográfico e documental de natureza qualitativa. O campo de pesquisa está diretamente relacionado à educação e portarias inerentes a programas PIBID gerados no período de 2013 até hoje (2018), constituindo-se nos nossos objetos de pesquisa.

\section{Resultados e Discussão}

\section{a. Sobre as Portarias no 096 de 18 de julho de 2013 e nº 46 de 11 de abril de 2016.}

A Portaria $n^{\circ} 096$ de 18 de julho de 2013 veio aperfeiçoar e atualizar as normas do Programa PIBID, emitindo o regulamento para implementação nas IES, contemplando objetivos muito importantes para a formação docente, são estes:

$$
\begin{aligned}
& \text { I - incentivar a formação de docentes em nível superior para a educação básica, } \\
& \text { II - contribuir para a valorização do magistério; } \\
& \text { III - elevar a qualidade da formação inicial de professores nos cursos de licenciatura, } \\
& \text { promovendo a integração entre educação superior e educação básica; } \\
& \text { IV - inserir os licenciandos no cotidiano de escolas da rede pública de educação, } \\
& \text { proporcionando-lhes oportunidades de criação e participação em experiências } \\
& \text { metodológicas, tecnológicas e práticas docentes de caráter inovador e } \\
& \text { interdisciplinar que busquem a superação de problemas identificados no processo de } \\
& \text { ensino-aprendizagem; } \\
& \text { V - incentivar escolas públicas de educação básica, mobilizando seus professores } \\
& \text { como co-formadores dos futuros docentes e tornando-as protagonistas nos processo } \\
& \text { de formação inicial para o magistério; } \\
& \text { VI - contribuir para a articulação entre teoria e prática necessárias à formação dos } \\
& \text { docentes, elevando a qualidades das açães acadêmicas nos cursos de licenciatura; } \\
& \text { VII - contribuir para que os estudantes de licenciatura se insiram na cultura escolar } \\
& \text { do magistério, por meio da apropriação e da reflexão sobre instrumentos, saberes e } \\
& \text { peculiaridades do trabalho docente. (PORTARIA } 096 \text { DE } 18 \text { DE JULHO DE 2013, } \\
& \text { p.2-3) }
\end{aligned}
$$

A Portaria $\mathrm{n}^{\circ} 46$ de 11 de abril de 2016 propunha exatamente o mesmo que a Portaria nº 096/2013, acrescentando, porém, dois parágrafos: 
VIII. articular-se com os programas de formação inicial e continuada de professores da educação básica, de forma a contribuir com a criação ou com o fortalecimento de grupos de pesquisa que potencialize a produção de conhecimento sobre ensinar e aprender na Educação Básica;

IX. comprometer-se com a melhoria da aprendizagem dos estudantes nas escolas onde os projetos institucionais são desenvolvidos.

Podemos ver clara relevância do programa PIBID na vida de um licenciando, não somente desde o ponto de vista de sua formação, senão dos benefícios que recaem sobre todos os que desenvolvem um rol: IES, coordenação institucional, coordenação de área, licenciandos, supervisores da escola básica, estudantes da escola básica e comunidade.

No artigo $8^{\circ}$ da Portaria $n^{\circ}$ 096/2013, recomendava-se que as IES fossem desenvolver o PIBID nas escolas que tivessem obtido Índice de Desenvolvimento da Educação Básica (IDEB) abaixo da média nacional ${ }^{6}$ e nas escolas bem sucedidas, com a finalidade de que as diferentes realidades sejam apreendidas e que se possa contribuir para a melhora do IDEB. De outro modo, a Portaria $n^{\circ} 46 / 2016$ sequer menciona prioridade consoante o IDEB, se limitando a definir carga horária de 10 horas semanais para o desenvolvimento de atividades pelos bolsistas, sendo seis horas nas escolas de educação básica e quatro horas na IES. Em oposição a essas duas Portarias, a Portaria Gab nº 45 de 12 de março de 2018, determina carga horária de, pelo menos, 32 horas mensais.

De acordo com o artigo 10 da Portaria $n^{\circ}$ 096/2013, cada subprojeto deve indicar um ou mais níveis de ensino da Educação Básica como centro de seu desenvolvimento. Em contrapartida, as Portarias no 046/2016 e n 45/2018 não fazem menção a essa característica para os subprojetos.

Com relação aos cursos de licenciatura contemplados pelo PIBID, em 2013 totalizavam 29, enquanto que em 2016 a Portaria n $46 / 2016$ baixou esse número para apenas nove, além de elaborar uma formatação diferente, relacionando o nível de ensino com eixos estruturantes, sub-eixos estruturantes e licenciaturas articuladoras “que são as responsáveis pelas atividades integradas, pela unicidade e pela organicidade dos subprojetos do sub-eixo estruturante" (PORTARIA 46/2016). Daí, partindo da própria compreensão de como realizar em campo e na vida real da educação, das IES e da aplicabilidade. A estruturação proposta

\footnotetext{
${ }^{6}$ O Índice de Desenvolvimento da Educação Básica (IDEB) é um indicador que mede a qualidade da educação. Foi criado em 2007 e pensado para facilitar o entendimento de todos, estabelecido numa escala que vai de zero a dez. Disponível em: <http://portal.mec.gov.br/component/content/article?id=273:como-melhorar-seu-ideb-sp1143596099>. Acesso em: 02 set. 2018.
} 
nessa Portaria n ${ }^{\circ}$ 046/2016 significava para as licenciaturas um obstáculo difícil de livrar, de acordo com a forma como deviam ser organizados, limitavam-se áreas de conhecimento, obrigando à junção com outras, mantendo uma coordenação única. Isso implicava, por exemplo, em que um coordenador de área de História também coordenasse Geografia ou Sociologia etc. Vejamos o quadro 1:

Tabela 1: Licenciaturas contempladas no PIBID 2013 e PIBID 2016. Fonte: Própria

\begin{tabular}{|c|c|}
\hline $\begin{array}{l}\text { Conforme Edital 061/2013 } \\
\text { Licenciaturas contempladas no PIBID } 2013\end{array}$ & $\begin{array}{l}\text { Conforme Portaria 46/2016 } \\
\text { Licenciaturas contempladas no PIBID } 2016\end{array}$ \\
\hline $\begin{array}{l}\text { Artes Plásticas e Visuais - Biologia - Ciências - } \\
\text { Ciências Agrárias - Ciências Sociais - Dança - } \\
\text { Educação Especial - Educação Física - } \\
\text { Enfermagem - Ensino Religioso - Filosofia - } \\
\text { Física - Geografia - História - Informática - } \\
\text { Letras - Alemão - Letras - Espanhol - Letras - } \\
\text { Francês - Letras Inglês - Letras Italiano - Letras } \\
\text { Português } \\
\text { Matemática - Música - Pedagogía - Psicologia - } \\
\text { Química - Teatro - Interdisciplinar }\end{array}$ & $\begin{array}{l}\text { Pedagogia } \\
\text { Letras } \\
\text { Matemática } \\
\text { Ciências, História, Geografia } \\
\text { Biologia, Química, Física } \\
\text { Filosofia, Sociologia }\end{array}$ \\
\hline
\end{tabular}

De acordo com o artigo 11 do Edital $n^{\circ}$ 061/2013, no sub tópico 4.2, cada subprojeto deveria estar composto por, no mínimo, cinco estudantes de licenciatura, um coordenador de área e um docente supervisor, composição que considerada bastante apropriada para o tipo de atividades propostas. O número de cinco estudantes para serem acompanhados por um docente supervisor é adequado, ficando cada coordenador de área (IES) encarregado de orientar 20 estudantes.

Essa realidade mudou com a proposta contida na Portaria $n^{\circ} 46 / 2016$, pois cada coordenador de área deveria orientar no mínimo 20 e no máximo 30 estudantes: se não existisse esse mínimo, o subprojeto também não existiria. E ainda, cada supervisor deveria acompanhar no mínimo 10 estudantes - o dobro do que acompanhava no PIBID 2013 - e no máximo 15. Na gerência institucional do projeto que tivesse cinco coordenadores de área, um desses deveria assumir a coordenação institucional, além da coordenação de área, sem ter qualquer reconhecimento de qualquer forma, como carga horária, bolsa extra, etc. Além disso, na Portaria $n^{\circ} 46 / 2016$ se extinguiram as bolsas de coordenador institucional e coordenador geral, que passariam a ser responsabilidade de um coordenador de área, gerando para este uma verdadeira sobrecarga, entendendo a complexidade de acompanhamento desse novo PIBID.

Segundo a Portaria 096/2013, a seleção do projeto institucional das IES seria feita por 
chamada pública, concretizando-se no edital $n^{\circ} 061 / 2013^{7}$, o mesmo que em seu Artigo 13, sub tópicos I, II, IV, V, VI e VII deveria ser atendido apresentando a estratégia de atuação dos bolsistas a ser adotada; a descrição das ações de inserção PIBID; as formas de seleção, acompanhamento e avaliação dos bolsistas; o plano de trabalho para a aplicação de recursos do programa; a descrição da contrapartida da IES, as formas de registro dos egressos. O sub tópico III chamou especial atenção ao determinar que a IES precisará informar "a estratégia a ser adotada para que o bolsista aperfeiçoe o domínio da língua portuguesa, incluindo leitura, escrita e fala" o que significa que nos planos do governo e no contexto do programa PIBID haveria uma clara e direta preocupação por aperfeiçoar a língua portuguesa nas suas principais competências para os licenciandos.

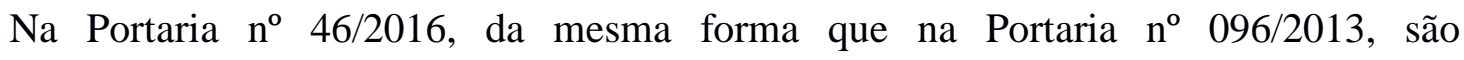
contemplados, basicamente, os mesmos critérios de seleção do projeto institucional, porém muito mais enriquecidos e ampliados, articulando também programas do MEC e sistemas de ensino, prezando evitar dispersão de esforços e contando com a contrapartida das IES. Porém, nesta Portaria no 46/2016 não se faz menção nenhuma à questão de "aperfeiçoamento da língua portuguesa, incluindo leitura, escrita e fala".

Prevê-se como atribuições da IES, na Portaria nº 096/2013, listadas no Artigo 22, de I a XIII, ações que se traduzem em dar condições logísticas, de assessoria, divulgação, respaldo, identidade institucional e de certificação para as atividades do PIBID, além das quais ainda poderia oferecer apoio com estagiários, redução de carga horária para os coordenadores, bolsas adicionais para os estudantes não contemplados, transporte etc. Na Portaria nº 46/2016, não é diferente, porém não há menção alguma a oferecer apoio de estagiários, redução de carga horária dos coordenadores e bolsas adicionais para estudantes não contemplados.

No artigo 24 da Portaria $n^{\circ}$ 096/2013 consta, em I a V, os itens que podiam ser financiados pelo PIBID em favorecimento dos bolsistas - estudantes ou docentes envolvidos com o programa, para poder desenvolver atividades acadêmicas em congressos, por exemplo, como diárias e passagens, gastos de embarque e quaisquer outras despesas relacionadas com participação em eventos. Essa participação deve ter como a finalidade a apresentação de trabalhos, ministração de minicursos, proferimento de palestras inerentes ao PIBID, inclusive para palestrantes externos à IES que, igualmente, porém de forma bem

\footnotetext{
7 Edital $\quad$ no 061/2013. Disponível em: <https://www.capes.gov.br/images/stories/download/editais/Edital_061_2013_PIBID.pdf>. Acesso em: 02 set. 2018.
} 
generalizadora na redação dos Artigos, na Portaria 46/2016, também são contemplados.

Fica expresso na Portaria $n^{\circ}$ 096/2013 que é absolutamente vedada a possibilidade de financiar itens de contratação de consultorias, recepcionistas etc., pagamento de luz, internet, água, telefone, correios, limpeza, compra de material de limpeza - exceto se for para atividades experimentais -, também não higienização, ornamentação, brindes, placas comemorativas, troféus e medalhas etc. Porém, é permitida a compra de lanches para alunos da escola básica quando tiver atividade promovida pelo PIBID extraclasse ou contra turno ou nas férias escolares. A Portaria n 046/2016 não aborda diretamente este assunto.

Quanto à seção que trata das modalidades e da duração das bolsas, conforme a Portaria n 096/2013 - artigos de 27 a 32 -, fixa para o estudante a duração de até 24 meses, podendo este prazo ser prorrogado por igual período. Já para a coordenação e supervisão, o prazo fixado é de até 48 meses, também prorrogável por igual período. São contempladas as figuras de 01 (um) coordenador institucional (CI); 01 (um) coordenador de gestão (CG) para atender de 01 a 200 bolsistas; 01 (um) coordenador de área (CA) para atender de 05 a 20 estudantes e 01 (um) supervisor para atender de 05 a 10 estudantes.

Sobre o mesmo tema, na Portaria n $n^{\circ} 46 / 2016$ foi definido que a duração de participação no Programa PBID para estudantes seria de até 12 meses, prorrogáveis por igual período. A permanência além desse prazo total de 24 meses, seria decisão da CAPES

Para conceder a bolsa a um CI ou a um CG, segundo a Portaria $n^{\circ}$ 096/2013, este precisa ser mestre ou doutor, efetivo, em exercício no ensino superior por no mínimo três anos, docente de disciplina em curso de licenciatura da IES, experiência em formação de professores, execução de projetos de ensino, orientação de estágio, docente ou gestor pedagógico na educação básica e ter produção na área, ter disponibilidade para o programa, não ocupar cargos de gestão na IES e ter currículo lattes. No caso da Portaria n 46/2016 o $\mathrm{CI} / \mathrm{CG} / \mathrm{CA}$, três funções em uma pessoa, devia atender os mesmos requisitos previstos na Portaria $n^{\circ}$ 096/2013.

No caso de um CA e em ambas as portarias em questão, estes docentes devem possuir graduação ou pós-graduação na área do subprojeto e atender os demais requisitos de um CI ou CG. Assim mesmo, para conceder bolsa a um supervisor, que é o professor da escola pública de ensino básico, precisa possuir licenciatura, preferencialmente na área do subprojeto, ser efetivo do serviço publico, ter no mínimo dois anos de experiência ministrando disciplina da área do subprojeto e ser selecionado pela IES para o PIBID. 
Tanto na Portaria $n^{\circ}$ 096/2013 quanto na Portaria $n^{\circ} 46 / 2016$, para que os estudantes tenham bolsa concedida precisam estar regularmente matriculados em curso de licenciatura na área do subprojeto. Apenas para a Portaria no 096/2013 o aluno deve ter concluído pelo menos o $1^{\text {o }}$ semestre do curso. Em ambas, o estudante deve ter bom desempenho acadêmico, demonstrado no histórico escolar, e ser aprovado em processo seletivo PIBID da IES. Porém aqueles que estiverem em débito de qualquer natureza com a CAPES ou outras instituições públicas de fomento, ou estiver em licença-prêmio, maternidade ou médica acima de 14 dias, ou ainda, acumular bolsa concedida por qualquer agência de fomento público, não pode participar do programa PIBID.

Sobre os deveres dos bolsistas CI, CG, CA, supervisores e estudantes, segundo a Portaria n ${ }^{\circ}$ 096/2013 - Seção V -, artigos 39 a 43, chama a nossa atenção o sub tópico IV do Art. 39, 40, 43 e 41 no IV, que diz "atentar-se à utilização do português de acordo com a norma culta, quando se tratar de comunicação formal do programa" acrescentando "[...] ou demais atividades que envolvam a escrita" no art. 42. É visível a preocupação pela produção no contexto PIBID em língua portuguesa formal ou culta. Difícil entender o porquê desta ênfase. Apenas essa anotação não aparece na Portaria n 46/2016 e o cancelamento da bolsa PIBID se daria por descumprimento de obrigações, licença ou afastamento, abandono, trancamento, desligamento do curso cabendo a possibilidade de devolução se houver pagamento de valores indevidos ou a mais.

A oscilação que apresentam as Portarias $n^{\circ}$ 096/2013 e $n^{\circ}$ 046/2016 a respeito do número de horas de dedicação ao PIBID por parte dos estudantes é sensível. Para o PIBID 2013 devia-se cumprir no mínimo 8 horas, porém para o 2016, segundo a Portaria 46/2016 se deveria cumprir 10 horas, sendo obrigatoriamente 6 horas na escola, sem que isso significasse prejuízo para atender as atividades acadêmicas do discente.

Diante do exposto neste apartado, aclaramos e afirmamos que a Portaria $n^{\circ} 46 / 2016$, não gerou chamada pública por ter sido anulada, como foi dito antes, porém pertinente se faz notar neste trabalho as razões que puderam ter gerado a rejeição da comunidade acadêmica nacional a respeito dessa Portaria.

\section{b. Sobre a Portaria Gab no 45 de 12 de março de 2018.}

Com a Portaria $n^{\circ} 45$ de 2018, fica revogada a Portaria $n^{\circ} 096$ de 2013. No novo documento, de 2018, se apresentam em simultâneo, dois programas: Residência Pedagógica e 
PIBID; sobre este último a importante mudança é que só podem participar do programa os estudantes que estejam na primeira metade de curso de licenciatura, pública ou privada, incentivando assim à participação do licenciando em sala de aula desde o início do curso, familiarizando-o com seu futuro ambiente de trabalho e unindo a teoria à prática.

Pontuando outras mudanças, contrastando com a Portaria $n^{\circ}$ 096/2013 e esquivando esse contraste com a Portaria $n^{\circ} 46 / 2016$, por razões óbvias, destaca-se a necessidade de que as IES, para participar do PIBID, devem possuir Conceito de Curso ou Conceito Preliminar de Curso igual ou superior a 3 (três), valendo o mesmo para o Conceito Institucional (CI) ou Índice Geral de Curso (IGC) das IES.

Sobre a concessão de bolsas, nesta nova Portaria fica excluída a coordenação de gestão (CG), ao mesmo tempo em que é reconsiderada a função de CI e mantém as outras modalidades. Exige o cadastro na Plataforma Freire de todos os participantes do programa PIBID e é criado um Sistema de Cadastro de Bolsas ao que todos os participantes têm acesso e são responsáveis pelos dados neles contidos, podendo ter acesso às informações que acharem necessárias.

Houve reconsideração e reformulação da participação dos cursos de licenciatura, ficando mais parecido ao que estava previsto no PIBID 2013, o que gerou satisfação e confiança no Programa, embora não tenha contemplado as áreas de Dança, Educação Especial, Enfermagem, Ensino Religioso, Letras Alemão, Italiano e Libras, Música, Psicologia, Teatro e Licenciatura Interdisciplinar, como podemos apreciar no quadro 2:

Quadro 2: Licenciaturas contempladas no PIBID 2013 e PIBID 2018. Fonte: Própria

Segundo Edital 061/2013

Licenciatura contempladas no PIBID 2013

Artes Plásticas e Visuais - Biologia - Ciências Ciências Agrárias - Ciências Sociais - Dança Educação Especial - Educação Física Enfermagem - Ensino Religioso - Filosofia Física - Geografia - História - Informática Letras - Alemão - Letras - Espanhol - Letras Francês - Letras Inglês - Letras Italiano - Letras Português - Matemática - Música - Pedagogia Psicologia - Química - Teatro - Interdisciplinar
Segundo Portaria 45/2018 Licenciatura contempladas no PIBID 2018

Arte, Biologia, Ciências, Educação Física, Filosofia, Geografia, História, Informática, Língua Espanhola, Língua Inglesa, Matemática, Química ou Sociologia ou, ainda, cursos de Pedagogia, Licenciatura Intercultural Indígena e Licenciatura em Educação do Campo

Sem entrar agora no mérito de positividade ou negatividade, se tem visto mudanças, angústias e reconsiderações que aconteceram no PIBID entre 2013 e 2018, porém muitas diretrizes se mantiveram e estudantes usufruem das possibilidades de vivenciar experiências na docência, durante a formação, estando inseridos na realidade da educação pública de hoje. 


\section{Conclusões}

Em virtude dos fatos mencionados levantados a partir da análise das portarias PIBID de 2013 a 2018, concluímos que o Programa PIBID é um grande acerto por parte do MEC que vem contribuir de forma muito importante na formação docente dos licenciandos, oportunizando uma aliança entre a teoria e a pratica.

Concluímos que as Portarias $n^{\circ}$ 096/2013 e a atual $n^{\text {o }}$ 045/2018 têm conservado uma mesma linha de planejamento, que foi traçada pensando de fato na realidade da formação dos envolvidos no programa. Porém a primeira contemplou com olhar mais justo a densidade de trabalho para os coordenadores institucionais e de área. Ainda ressaltando que na Portaria $n^{\circ}$ 045/2018 a função do CG foi extinta.

Percebemos uma clara evolução na sistematização do programa PIBID e que nessa evolução houve momentos difíceis gerados a partir da Portaria $n^{\circ} 46 / 2016$ que logo mais foi anulada como resposta da comunidade acadêmica às diretrizes nela contidas, afinal representava um retrocesso no Programa, que é tão importante para a Educação.

Achamos pertinente dizer que nos interessamos por fazer este trabalho em virtude de não termos visto produção neste sentido de análise e reflexão diacrônico do Programa PIBID, e acreditamos ser importante, pois possibilita reflexões e destaca que ainda existe muito mais a dizer, mostrar e analisar, objetivando contribuir positivamente para que este Programa se torne permanente, uma vez que cumpre satisfatoriamente o propósito para o qual foi criado.

\section{Referências}

BRASIL. Decreto 7219 de 24 de junho de 2010. Dispõe sobre o Programa Institucional de Bolsas a Iniciação a Docência (PIBID) e dá outras providências. Brasília: MEC, 2010.

Decreto 6755 de 27 de janeiro de 2009. Institui a Política Nacional de Formação de Profissionais do Magistério da Educação Básica, disciplina a atuação da Coordenação de Aperfeiçoamento de Pessoal de Nível Superior -CAPES no fomento a programas de formação inicial e continuada, e dá outras providências. Brasília: MEC, 2009

MEC. Resolução CNE/CP 1 de 2002. Institui Diretrizes Curriculares Nacionais para a Formação de Professores da Educação Básica, em nível superior, curso de licenciatura, graduação plena. Brasília: MEC, 2002.

Ministério da Educação. Coordenação de aperfeiçoamento de pessoal de nível

superior (Capes). Edital $\mathbf{n}^{\mathbf{0}}$ 061/2013. Brasília, 2013. Disponível em: <https://www.capes.gov.br/images/stories/download/editais/Edital_061_2013_PIBID.pdf>. Acesso em: 13 set. 2018. 
Ministério da Educação. Coordenação de aperfeiçoamento de pessoal de nível superior (Capes). Edital no 7/2018. Brasília, 2018. Disponível em: <http://www.capes.gov.br/images/stories/download/editais/27032018-Edital-7-PibidAlteracao-II.pdf>. Acesso em: 13 set. 2018.

Ministério da Educação. Coordenação de aperfeiçoamento de pessoal de nível superior (Capes). Pibid e residência pedagógica anunciam resultado preliminar. Disponível em: <http://www.capes.gov.br/sala-de-imprensa/noticias/8869-pibid-e-residenciapedagogica-anunciam-resultado-preliminar>. Acesso em: 17 set. 2018.

FORPIBID contra a opressão e pela coragem de formar professores. Disponível em: <https://peticaopublica.com.br/pview.aspx?pi=pibid-fica>. Acesso em: 13 set. 2018.

GATTI, Bernadete A.; ANDRÉ, Marli E. D. A.; GIMENES, Nelson A. S.; FERRAGUT, Laurizete. Um estudo avaliativo do Programa Institucional de Bolsa de Iniciação à Docência (Pibid). Vol. 41 - São Paulo: FCC/SEP, 2014. 120 p.

TORKANIA, Mariana. MEC vai cancelar portaria que muda regras do pibid, diz secretária executiva. Disponível em: $<$ http://agenciabrasil.ebc.com.br/educacao/noticia/2016-06/mec-vai-cancelar-portaria-quemuda-regras-do-pibid-diz-secretaria-executiva>. Acesso em: 13 set. 2018. 